\title{
Luminal cholera toxin alters motility in isolated guinea-pig jejunum via a pathway independent of $5-\mathrm{HT}_{3}$ receptors
}

\section{Candice Fung, Melina Ellis and Joel C. Bornstein*}

Department of Physiology, University of Melbourne, Parkville, VIC, Australia

\section{Edited by:}

L. Ashley Blackshaw, University of

Adelaide, Australia

Reviewed by:

Paul P. Bertrand, University of

New South Wales, Australia

David Linden, Mayo Clinic, USA

${ }^{*}$ Correspondence:

Joel C. Bornstein, Department of

Physiology, University of Melbourne,

Parkville, VIC 30101, Australia.

e-mail: j.bornstein@unimelb.edu.au
Cholera toxin (CT) is well established to produce diarrhea by producing hyperactivity of the enteric neural circuits that regulate water and electrolyte secretion. Its effects on intestinal motor patterns are less well understood. We examined the effects of luminal CT on motor activity of guinea-pig jejunum in vitro. Segments of jejunum were cannulated at either end and mounted horizontally. Their contractile activity was video-imaged and the recordings were used to construct spatiotemporal maps of contractile activity with CT $(1.25$ or $12.5 \mu \mathrm{g} / \mathrm{ml})$ in the lumen. Both concentrations of CT induced propulsive motor activity in jejunal segments. The effect of $1.25 \mu \mathrm{g} / \mathrm{ml}$ CT was markedly enhanced by co-incubation with granisetron (5-HT antagonist, $1 \mu \mathrm{M}$ ), which prevents the hypersecretion induced by CT. The increased propulsive activity was not accompanied by increased segmentation and occurred very early after exposure to $\mathrm{CT}$ in the presence of granisetron. Luminal CT also reduced the pressure threshold for saline distension evoked propulsive reflexes, an effect resistant to granisetron. In contrast, CT prevented the induction of segmenting contractions by luminal decanoic acid, so its effects on propulsive and segmenting contractile activity are distinctly different. Thus, in addition to producing hypersecretion, CT excites propulsive motor activity with an entirely different time course and pharmacology, but inhibits nutrient-induced segmentation. This suggests that CT excites more than one enteric neural circuit and that propulsive and segmenting motor patterns are differentially regulated.

Keywords: cholera toxin, intestinal motility, peristalsis, segmentation, $5-\mathrm{HT}_{3}$ receptors, serotonin

\section{INTRODUCTION}

Cholera toxin (CT) exerts much of its pathogenic effects via the enteric nervous system, acting to produce massively increased firing of secretomotor neurons and hence hypersecretion leading to severe diarrhea (for reviews see Lundgren and Jodal, 1997; Farthing, 2000, 2002). The increased firing is partly due to a long-term increase in excitability of secretomotor neurons following luminal incubation with CT, an effect prevented by co-incubation of CT with tetrodotoxin (Gwynne et al., 2009). Thus, CT produces neural activity during the incubation period, perhaps even before the enhanced secretion. This may alter motility.

While CT has a dramatic effect on water and electrolyte secretion, its effects on motility are less obvious and have sometimes been ascribed to the distension produced by an increased liquid load in the intestinal lumen. Most studies to date have been performed in vivo and lacked the spatial resolution needed to fully characterize organized motility patterns and their relationships. For example, Mathias and colleagues identified a migrating action potential complex in rabbit ileum in vivo produced by CT and other toxic agents (Mathias et al., 1977, 1982; Burns et al., 1978; Reeves-Darby et al., 1995), but how this relates to normal propulsive contractions is unclear. In contrast, Cowles and Sarna $(1990 \mathrm{a}, \mathrm{b})$ reported that $\mathrm{CT}$ decreased propagating contractions after a meal in the jejunum of conscious dogs, but what was happening between their recording sites (separated by $4-20 \mathrm{~cm}$ ) is uncertain. More recently, Kordasti et al. (2006) reported that distension of rat upper small intestine after $2 \mathrm{~h}$ of luminal CT incubation in vivo induced clusters of contractions that were absent in control conditions. The contraction clusters were enhanced by blocking $5-\mathrm{HT}_{3}$ receptors, in direct contrast to the abolition of CT-induced hypersecretion produced by this blockade in the same preparations. However, this study also lacked spatial resolution as contractions were identified as pressure changes recorded at a single point, so whether the contractions were propagating (propulsive) or stationary (segmenting) could not be determined. Thus, while CT alters motility patterns, these patterns have not been characterized in relation to normal intestinal motility.

Use of video imaging to construct spatiotemporal maps of intestinal diameter has allowed unprecedented resolution and characterization of motility patterns in different intestinal preparations in vitro. These include the rat stomach (Lentle et al., 2010), the haustrated rabbit colon (Lentle et al., 2008), chicken cecum (Janssen et al., 2009), the duodenum, jejunum, ileum, and colon of the mouse (Abdu et al., 2002; Roberts et al., 2008, 2010; Keating and Spencer, 2009; Neal et al., 2009) and the small intestine of guinea-pigs (Hennig et al., 1999; Gwynne et al., 2004; Gwynne and Bornstein, 2007b). These studies have identified several different organized motility patterns in addition to the often studied peristaltic reflex. In the duodenum and jejunum of the guinea-pig, five distinct motor patterns can be identified when a fatty acid or an amino acid is present in the lumen. These can be broadly divided into propulsive contractions initiated at the cut end of an isolated intestinal segment and propagating rapidly to the other end and segmenting contractions that are either localized stationary 
contractions or contractions that propagate slowly over $2-3 \mathrm{~cm}$ (Gwynne et al., 2004; Gwynne and Bornstein, 2007b). By contrast saline distension evokes only propulsive motor patterns (Hennig et al., 1999; Gwynne et al., 2004).

The present study aimed to characterize motility patterns induced by luminal CT, to test whether CT modifies the motility patterns evoked in guinea-pig jejunum by distension or intraluminal nutrient and to determine if these actions of CT are mediated via $5-\mathrm{HT}_{3}$ receptors.

\section{MATERIALS AND METHODS}

The methods for recording motility in this study were essentially identical to those described by Gwynne et al. (2004). Briefly, guinea-pigs of either sex (200-350 g) were rapidly killed by stunning followed by cutting the carotid arteries and spinal cord, a procedure approved by the University of Melbourne Animal Experimentation Ethics Committee according to guidelines of the National Health and Medical Research Council of Australia. Two adjacent segments of jejunum $(6-7 \mathrm{~cm})$ were removed, cannulated at both ends and mounted in horizontal recording chambers. The oral cannula was connected to a reservoir of physiological saline that could be raised and lowered to alter the intraluminal pressure within the segment. The anal end was connected to an outflow tube that provided a maximum of $2 \mathrm{~cm} \mathrm{H}_{2} \mathrm{O}$ back-pressure. The reservoir was closed, with a glass tube open at either end inserted from the top. The bottom of the tube was kept below the surface of the saline in the reservoir so solution drawn from the reservoir was replaced by air from the tube and the pressure head was set by the height of the bottom of the tube, not the surface of the saline. This kept the intraluminal pressure constant even when there was net propulsion of intraluminal content. The preparation was superfused with physiological saline (composition in $\mathrm{mM}$ : $\mathrm{NaCl} 118, \mathrm{KCl} 4.6, \mathrm{CaCl}_{2} 2.5, \mathrm{MgSO}_{4} 1.2, \mathrm{NaH}_{2} \mathrm{PO}_{4} 1, \mathrm{NaHCO}_{3}$ 25, D-Glucose 11, bubbled with $95 \% \mathrm{O}_{2}$ and $5 \% \mathrm{CO}_{2}$ ), which was also present in the oral reservoir and the lumen. Temperature in the organ bath was kept at $37^{\circ} \mathrm{C}$.

Video-recordings of the contractile activity of each segment were made with a Logitech Quickcam pro camera mounted 7-8 cm above the preparation (frame rate $30 \mathrm{~Hz}$ ) and stored as avi files on a PC. In house software was used to construct spatiotemporal maps of the diameter at each point along the segment [so called D maps (Janssen et al., 2009)], which were analyzed according to criteria established by Gwynne et al. (2004).

Segments were flushed clean with physiological saline and left to equilibrate in the organ bath for $30 \mathrm{~min}$. The pressure threshold for initiation of persistent propulsive contractions, the peristaltic reflex (Gwynne et al., 2004), was then determined by increasing the intraluminal pressure in $1 \mathrm{~cm} \mathrm{H}_{2} \mathrm{O}$ steps by raising the reservoir connected to the oral cannula. Each pressure step was held for $30 \mathrm{~s}$. The pressure at which consistent propulsive contractions were observed in three consecutive trials separated by 10 min was taken to be the threshold. Contractile activity was then recorded at resting pressure of $2 \mathrm{~cm} \mathrm{H}_{2} \mathrm{O}$ for $20 \mathrm{~min}$, before $20 \mathrm{ml}$ of saline (as a time control), saline containing CT (at either 1.25 or $12.5 \mu \mathrm{g} /$ $\mathrm{ml})$, or saline containing $1.25 \mu \mathrm{g} / \mathrm{ml}$ CT plus granisetron $(1 \mu \mathrm{M})$ was flushed into the lumen with the pressure then being returned to $2 \mathrm{~cm} \mathrm{H}_{2} \mathrm{O}$. After $5 \mathrm{~min}$, four $20 \mathrm{~min}$ recordings were taken. After $85 \mathrm{~min}$, the threshold measurements were repeated. These were followed by two $20 \mathrm{~min}$ recording periods. The saline alone was a control for effects due to changes in the mucosa.

In other experiments, saline containing decanoic acid (DA, $1 \mathrm{mM}$ ) or decanoic acid plus CT was infused into the intestinal lumen. Other elements of the protocol were identical.

\section{DATA ANALYSIS}

Contractile activity in each 20 min map was quantified using inhouse software that counted each contraction of whatever type. Subtypes of contractions, propulsive or segmenting, were identified by eye in each map. Propulsive contractions were taken to be constrictions that appeared at one end (usually the oral end) of the segment and propagated rapidly to the other end. Segmenting contractions were either localized constrictions that did not propagate or constrictions that slowly propagated less than half the length of the tissue segment in either direction (Gwynne et al., 2004). Mean frequencies and numbers of contraction subtypes were calculated from the data from 5 to 12 preparations. Each 20 min map is identified below by its mid-point time, e.g., the map made from the video recorded from 5 to $25 \mathrm{~min}$ after initial exposure to CT is termed the 15-min map and so on. Data were compared statistically using two-way ANOVA with a Bonferroni post hoc test for individual differences. $P$ values $<0.05$ were taken to indicate statistical significance.

\section{RESULTS CT RAPIDLY INCREASES CONTRACTILE ACTIVITY}

Inclusion of CT $(1.25 \mu \mathrm{g} / \mathrm{ml})$ in the luminal saline without increasing the baseline pressure significantly increased the overall frequency of contractions (Figures 1A,B,C). When numbers of contractions in each 20 min map were compared, two-way ANOVA indicated that significantly more contractions were seen with CT than in control $(P<0.0005)$, but that there was no effect of time $(P>0.9)$ nor was there an interaction between time and drug treatment $(P>0.6)$.

Cholera toxin-induced secretion is blocked by $5-\mathrm{HT}_{3}$ receptor antagonists in vivo (Buchheit, 1989; Kordasti et al., 2006) and a 5 - $\mathrm{HT}_{3}$ antagonist granisetron $(1 \mu \mathrm{M})$ prevents CT-induced hyperexcitability of submucosal secretomotor neurons in guinea-pig jejunum in vitro (Gwynne et al., 2009). In contrast, granisetron significantly increased the contractile activity induced by CT early in the exposure period (Figure 1D). Two-way ANOVA revealed significant time $(P<0.025)$ and drug dependent effects $(P<0.0001)$ with no interaction $(P>0.25)$. The post hoc Bonferroni test showed a significant difference between CT plus granisetron and CT alone in the 15 -min map point $(P<0.001)$ and not in the others. Thus, granisetron reveals an initial increase in contractile activity, which then declines to the ongoing elevated level of activity seen during continued exposure to CT. Luminal granisetron alone did not affect motility, the number of contractions in each map was indistinguishable from the time controls ( $n=6, P>0.5$, Figure 1D).

A higher concentration of CT $(12.5 \mu \mathrm{g} / \mathrm{ml})$ increased contractile activity to a greater extent than $1.25 \mu \mathrm{g} / \mathrm{ml} \mathrm{CT}(P<0.05$, no specific time point was significantly different in the post hoc test, data not shown). 


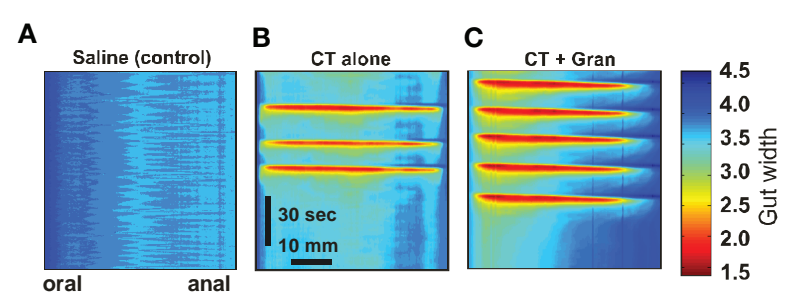

D

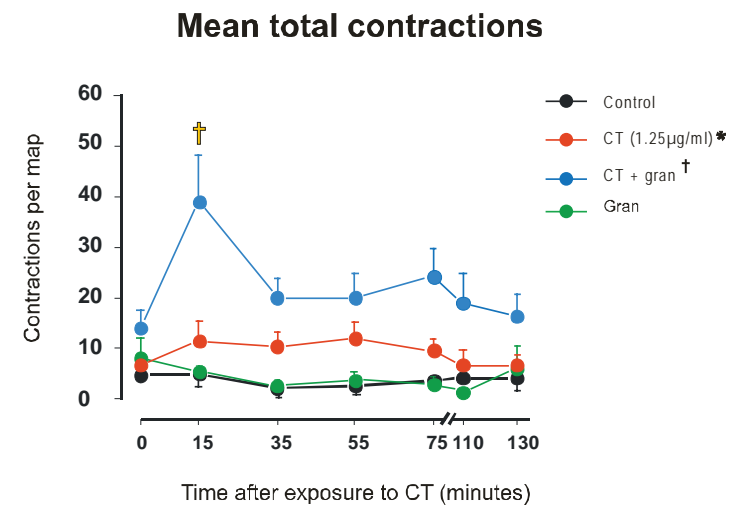

FIGURE 1 | Motor activity induced by luminal CT. (A-C) Spatiotemporal maps made during the 5-25 min after exposure to saline, $1.25 \mu \mathrm{g} / \mathrm{ml} \mathrm{CT}$ and $1.25 \mu \mathrm{g} / \mathrm{ml}$ CT plus $1 \mu \mathrm{M}$ granisetron, respectively. Each map shows $2 \mathrm{~min}$ of recording. $(\mathbf{B}, \mathbf{C})$ were selected to show bursts of propulsive contractions. (D) Mean numbers of contractions vs time for luminal saline (black), CT (1.25 $\mu \mathrm{g} /$ $\mathrm{ml}$, red), granisetron (1 $\mu \mathrm{M}$, gran, green), CT plus granisetron (CT + gran, blue). Whole curve differs from saline control $\left({ }^{*} P<0.0005\right)$, whole curve differs from CT alone ( $+P<0.0001)$, differs from control and CT alone $(\ddagger P<0.001)$.

\section{CONTRACTILE ACTIVITY INDUCED BY CT IS PROPULSIVE}

We counted the numbers of propulsive and segmenting contractions in each map to determine whether CT enhanced one or both types of activity. The increased activity induced by CT $(1.25 \mu \mathrm{g} /$ $\mathrm{ml}$ ) alone or with granisetron was almost entirely due to increased propulsive activity (Figure 2A).

The mean number of propulsive contractions per map increased significantly from close to 0 in the time controls to $6.2 \pm 2.0$ with CT $(1.25 \mu \mathrm{g} / \mathrm{ml})(P<0.0001$, two-way ANOVA with the post hoc test identifying a significant difference at $55 \mathrm{~min} P<0.05)$. When granisetron was also present propulsive contractions reached about 35 per map in the 15-min map with both drug $(P<0.0001)$ and time dependent $(P<0.00025)$ components and post hoc tests showing significant increases in contractile activity in the $15(P<0.001,35$, 55, and 75 min maps (all $P<0.05$ ).

In contrast, segmenting contractions were not elevated by either 1.25 (Figure 2B) or $12.5 \mu \mathrm{g} / \mathrm{ml} \mathrm{CT}$ over the entire period of exposure. However, in granisetron, a small, but significant rise in segmenting contractions was seen for the 75 and 110 min maps $(P<0.05$ in each case $)$.

The properties of the propulsive contractions were very similar to those previously described for guinea-pig jejunum (Gwynne et al., 2004). These contractions appeared predominantly at the oral end of the segment and propagated anally at about $20 \mathrm{~mm} / \mathrm{s}$, this was the same in all conditions.

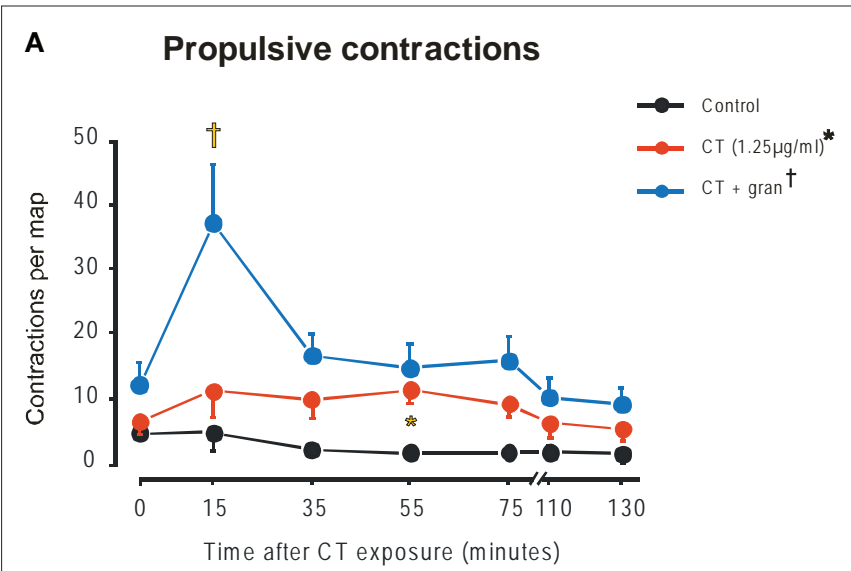

B

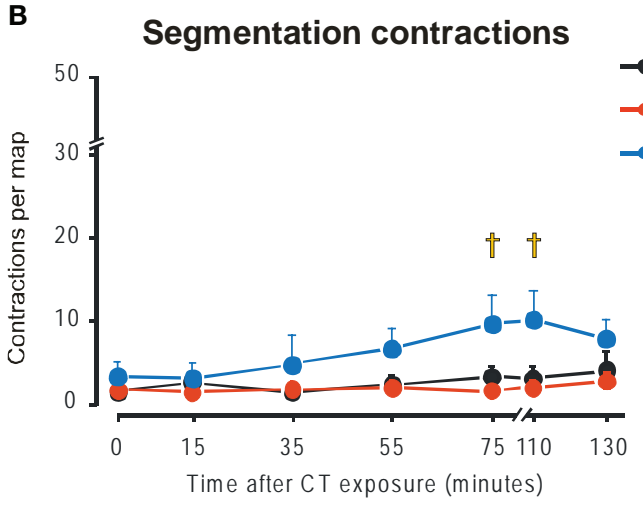

FIGURE 2 | Propulsive (A) and segmentation (B) contractions in control (black), CT (1.25 $\mu \mathrm{g} / \mathrm{ml}$, red), CT plus gran (blue). Curve differs from control ( $\left.{ }^{*}<<0.0001\right)$, curve differs from $\mathrm{CT}$ alone $(\dagger P<0.0001), \mathrm{CT}$ plus gran differs from $C T$ alone $(\ddagger P<0.001$, propulsive; $P<0.05$ segmentation).

The propulsive contractions were clustered together in bursts. We compared the number of contractions in each burst, the duration of the bursts, the frequency of contractions within the bursts and the intervals between the bursts to determine which parameters account for the increase in propulsive contractions. This analysis was undertaken for the 15-min maps as these showed the largest variation between treatments and hence were most likely to show variations in contraction properties. Burst durations were significantly greater for preparations exposed to CT plus granisetron $(240 \pm 70 \mathrm{~s}, n=11)$ than for CT alone $(110 \pm 40 \mathrm{~s}$, $n=6, P<0.05$, Welch test). Only 3 of the 15 -min maps from the time control experiments showed contraction bursts, so we did not compare the time controls and maps in the presence of CT. Granisetron significantly increased the frequency of contractions within a burst (CT plus granisetron $5.4 \pm 0.4$ per minute, CT $3.9 \pm 0.5$ per minute, time control $3.2 \pm 0.3$ per minute; $P<0.002$ CT plus granisetron vs time control, $P<0.05$ CT plus granisetron vs CT alone, Welch tests). Thus, there were more contractions per burst with CT plus granisetron $(22.5 \pm 6.7)$ than CT alone $(7.2 \pm 2.6)$ or the controls $(7.5 \pm 2.8)$. In contrast, interburst intervals did not differ between conditions (control $520 \pm 110 \mathrm{~s}$ $n=3$, CT alone $240 \pm 80 \mathrm{~s} n=6$, CT plus granisetron $360 \pm 100 \mathrm{~s}$ $n=8 ; P>0.3)$. 


\section{CT REDUCES THE PRESSURE THRESHOLD FOR PERISTALTIC REFLEXES}

To determine if CT alters responses to standard reflexes, we examined the threshold pressure required to evoke "persistent propulsive contractions" (Gwynne et al., 2004), i.e., peristaltic reflexes, before and after $85 \mathrm{~min}$ of exposure to CT or CT plus granisetron. The threshold pressure that evoked consistent propulsive contractions was significantly lower after exposure to CT or to CT plus granisetron $(P<0.05$ in each case, Figure 3A). Granisetron did not alter the effect of CT. The threshold pressure was also lower after $85 \mathrm{~min}$ of saline alone, but this difference was not significant $(P>0.05)$, consistent with earlier findings that threshold pressure for saline distension does not vary over at least 120 min (Gwynne et al., 2004).

Neither CT nor CT plus granisetron altered the propagation speeds of propulsive contractions evoked by distension, which were similar to those seen for spontaneous propulsive contractions. Furthermore, the diameter changes produced by the step increases in pressure were unaltered by CT with or without granisetron (Figure 3B). Thus, there was no change in compliance of the intestinal wall and changes in threshold were not secondary to accumulation of water in the lumen.

\section{CT PREVENTS THE INDUCTION OF SEGMENTATION BY DECANOIC ACID}

Decanoic acid induces prominent segmentation in the guinea-pig jejunum that typically begins after about $40 \mathrm{~min}$ (Gwynne et al., 2004; Gwynne and Bornstein, 2007a). To test if luminal CT affects this behavior, we infused a mixture of CT and decanoic acid (1 mM) into the lumen. CT produced a concentration-dependent reduction in segmentation induced by decanoic acid (Figure 4). Decanoic acid produced a time and treatment (both $P<0.0001$ ) dependent increase in contractile activity, which was significant for the $75(P<0.01), 110$ and 130 (both $P<0.001$ ) minute maps. This increase was depressed by $1.25 \mu \mathrm{g} / \mathrm{ml} \mathrm{CT}(P<0.0001)$ with major differences in the 110 and 130 min maps $(P<0.01, P<0.001$, respectively). The higher concentration of CT $(12.5 \mu \mathrm{g} / \mathrm{ml})$ was more effective (Figure $4 \mathrm{~B})$.

Decanoic acid increased both propulsive (Figure 4C, $P<0.0001$ ) and segmenting contractions (Figure 4D, $P<0.0001$ ) with the major effects being in the 75 and 130 min maps $(P<0.01$ in each case) and the 110 and $130 \mathrm{~min}(P<0.001$ in each case $)$, respectively. The only significant effect of CT on the propulsive contractions evoked by decanoic acid was that the higher concentration of CT increased propulsive contractions in 35 min maps $(P<0.05)$, before decanoic acid-induced motility appeared (Figure 4C). However, both concentrations of CT markedly depressed segmenting contractions evoked by decanoic acid (Figure 4D, $P<0.0001$ in each case) with the effect being seen in the 110 and 130 min maps $(P<0.0001$ in each case) and the higher concentration being much more effective $(P<0.0001)$.

\section{DISCUSSION}

This study provides strong evidence that luminal CT activates a motor pattern generating circuit that produces propulsive contractions within the guinea-pig jejunum and that this is largely

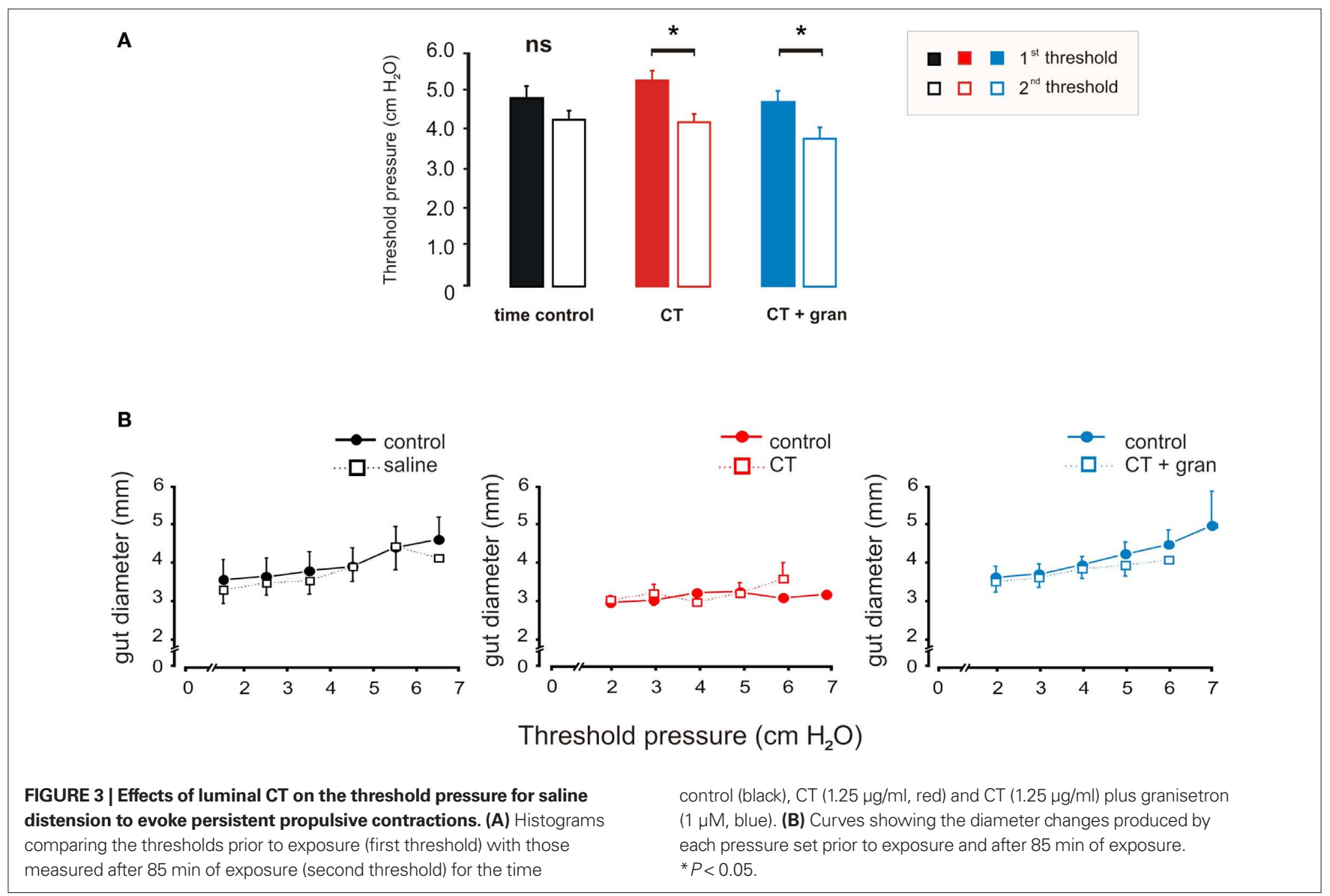


A

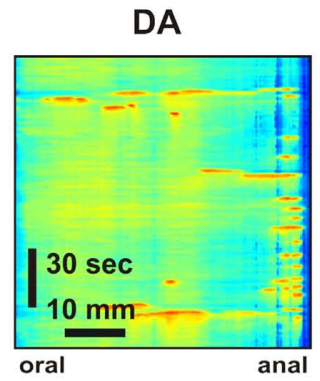

\section{DA + low CT}

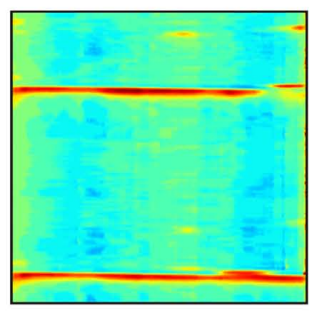

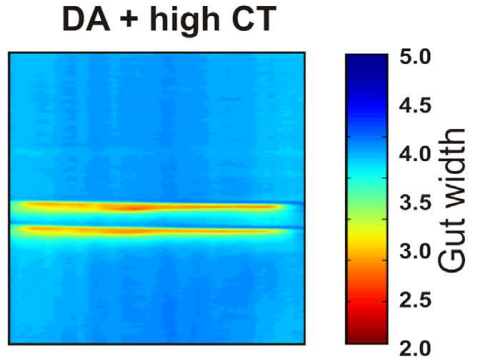

B

Mean total contractions

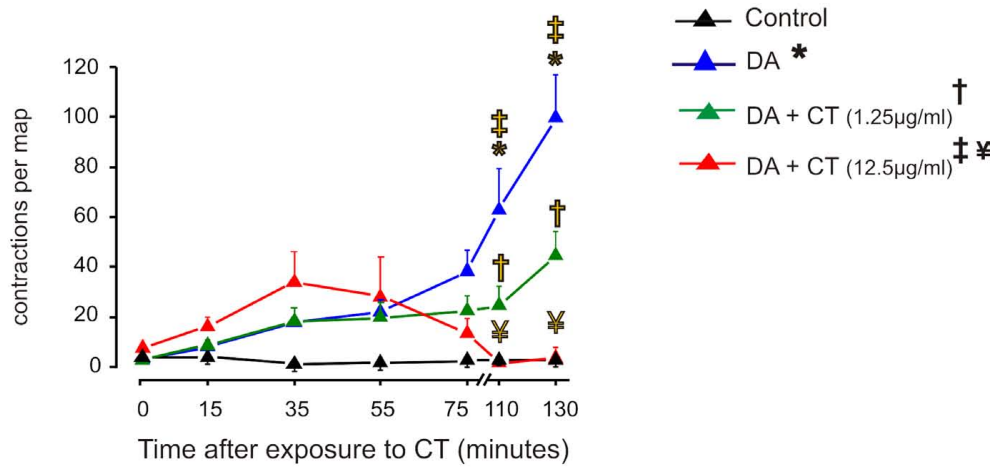

C

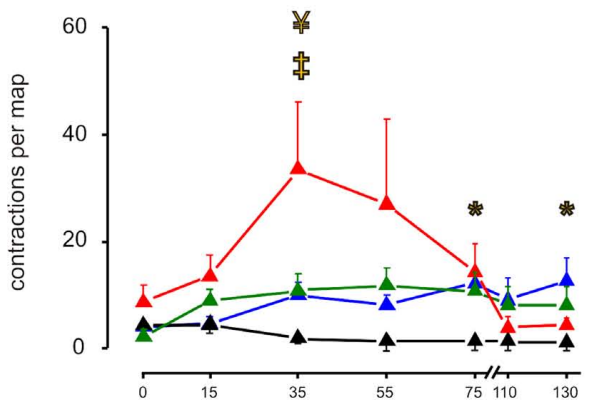

D Segmentation contractions

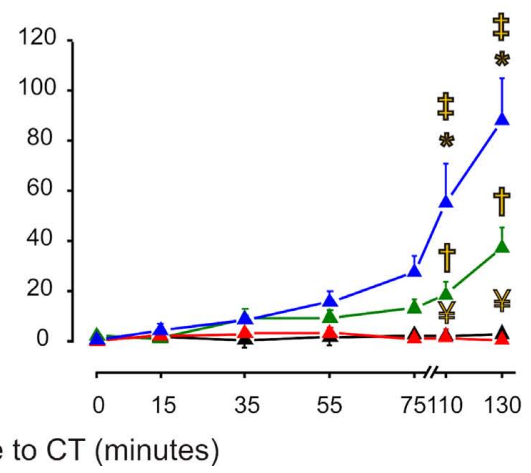

FIGURE 4 | Luminal CT depresses segmentation induced by decanoic acid (1 $\mathbf{~ m M , ~ D A ) . ~ ( A ) ~ T h r e e ~ m i n u t e ~ m a p s ~ o f ~ c o n t r a c t i l e ~ a c t i v i t y ~ t a k e n ~ a f t e r ~}$ 120-140 min of luminal DA alone, DA plus low CT $(1.25 \mu \mathrm{g} / \mathrm{ml})$ and DA plus CT $(12.5 \mu \mathrm{g} / \mathrm{ml})$. (B) Overall contractile activity against time (black - time control, blue - DA alone, green - DA + low CT, red - DA + high CT.

(C) Propulsive contractions; (D). Segmentation. Curves: DA vs control
( $\left.{ }^{*} P<0.0001\right), \mathrm{DA}+$ low $\mathrm{CT}$ vs DA ( $P<0.0001$, total contractions and segmentation; $\mathrm{P}>0.5$ propulsion), $\mathrm{DA}+$ high $\mathrm{CT}$ vs $\mathrm{DA}(\ddagger P<0.0001)$, $\mathrm{DA}+$ high $\mathrm{CT}$ vs $\mathrm{DA}+$ low $\mathrm{CT}(¥ P<0.0001)$. Individual points: DA vs control ( $P<0.01)$, DA + low CT vs DA ( $P<0.01)$, DA + high $\mathrm{CT}$ vs DA $(\ddagger P<0.001$, total contractions and segmentation; $P<0.5$, propulsion), DA + high CT vs $\mathrm{DA}+$ low CT $(¥ P<0.05)$. independent of the neural mechanisms mediating the hypersecretion induced by this toxin. The motility effects of CT differ markedly in time course and pharmacology from the hypersecretion evoked by CT, so these data support and extend the proposal that luminal CT excites more than one enteric neural pathway (Kordasti et al., 2006). Interestingly, the propulsive contractions evoked by CT were indistinguishable from propulsive contractions evoked by saline distension or luminal nutrient (Gwynne et al., 2004) suggesting that the toxin activates a normal motor program.

\section{DIFFERENT CIRCUITS MEDIATE MOTILITY AND SECRETION EVOKED BY LUMINAL CT}

Cholera toxin releases 5-HT from the mucosa (Turvill et al., $2000 \mathrm{~b}$ ), an effect blocked by the $5-\mathrm{HT}_{3}$ antagonist granisetron, and the mucosal terminals of myenteric intrinsic sensory neurons are excited by mucosally applied 5-HT via $5-\mathrm{HT}_{3}$ receptors (Bertrand et al., 2000; Bertrand and Bornstein, 2002). Myenteric intrinsic sensory neurons almost certainly mediate both motility reflexes evoked by distension and the suite of motor patterns including propulsive contractions and segmentation evoked by nutrients. 
Thus, it might be expected that effects of CT on secretion, which require 5- $\mathrm{HT}_{3}$ receptors (Buchheit, 1989; Mourad et al., 1995; Turvill et al., 1998; Kordasti et al., 2006), would be paralleled by effects on motility. Indeed, this was the starting hypothesis of the present study. The results obtained are in distinct contrast to this hypothesis.

Firstly, the most prominent motility effect of CT was seen 5-25 min after the initial exposure to the toxin, while effects of CT on secretion are very slow in onset (for initial studies see Field et al., 1972; Argenzio and Whipp, 1981). Indeed, recent studies of CT hypersecretion begin after $2 \mathrm{~h}$ of incubation with CT for this reason (e.g., Mourad et al., 1995; Turvill et al., 2000a,b,c; Kordasti et al., 2006). Further, the increased propulsive activity induced by $\mathrm{CT}$ in the presence of granisetron declines to a plateau within $40 \mathrm{~min}$, while CT-induced secretion begins at about $40 \mathrm{~min}$ and continues to rise for $60-90 \mathrm{~min}$. The rapid onset of the motility effects of CT shows that the slow onset of CT-induced secretion is not due to slow activation of enteric neural circuits.

The other major difference between the motility effects of CT and the hypersecretion is in the role of $5-\mathrm{HT}_{3}$ receptors. Granisetron, administered with CT, prevents hypersecretion (Mourad et al., 1995; Kordasti et al., 2006). By contrast, granisetron markedly increases propulsive motility due to luminal CT, but does not affect the reduction in pressure threshold for propulsive reflexes also produced by luminal CT.

The differences in responses to granisetron indicate that CT excites at least two distinct pathways involving $5-\mathrm{HT}_{3}$ receptors. One excites secretomotor activity, the other inhibits the propulsive motor activity that is revealed when $5-\mathrm{HT}_{3}$ receptors are blocked. A third pathway that activates propulsive motor activity and lowers the threshold for distension-evoked propulsive motor activity is independent of 5- $\mathrm{HT}_{3}$ receptors. Luminal 5-HT reduces the threshold for activation of propulsive reflexes and this is blocked by luminal, but not serosally applied, $5-\mathrm{HT}_{3}$ antagonists indicating that the $5-\mathrm{HT}$ is acting via $5-\mathrm{HT}_{3}$ receptors in the mucosal layers (Tuladhar et al., 1997). How this relates to our finding that CT reduces threshold via a $5-\mathrm{HT}_{3}$-independent mechanism is unclear.

There may be a fourth pathway activated by CT, because the toxin prevented the normal rise in segmenting motor activity induced by decanoic acid. In this case, however, we could not identify a role for $5-\mathrm{HT}_{3}$ receptors, because blockade of $5-\mathrm{HT}_{3}$ receptors also suppresses decanoic acid-induced motility (Ellis et al., 2009). Perhaps CT-induced 5-HT release desensitizes $5-\mathrm{HT}_{3}$ receptors, whose ongoing activation is needed for a build up of enteric neural activity that leads to segmenting motor activity.

\section{CT SELECTIVELY ACTIVATES PROPULSIVE MOTILITY}

There are clear differences between our results and previous studies. The most notable are our findings that CT enhances propulsive motility and suppresses nutrient-induced segmentation, which contrasts dramatically with reports that CT depressed propulsive motility and had no significant effect on fed state segmentation in dog jejunum in vivo (Cowles and Sarna, 1990a,b). The reasons for these opposing findings are unclear. They may reflect species differences, the disruption of the extrinsic innervation in isolated tissues or simply the differing time courses of the experiments (see below). Our results are more similar to those of previous work on rabbit terminal ileum in vivo, which indicated that CT produced an abnormal form of propulsive activity. However, again there are several differences. For example, propulsive motility did not appear in the rabbit ileum until $3 \mathrm{~h}$ after exposure to the toxin and reached a stable maximum after $4-5 \mathrm{~h}$, while we saw a transient increase in propulsive contractions within the first 5-25 min of exposure and this declined to a plateau with $2 \mathrm{~h}$ of exposure (Figure 2A). Further, the abnormal motility seen in the rabbit ileum consisted of single rings of contraction lasting up to $10 \mathrm{~s}$ that were repeated 8-12 times per hour, while the contractions seen in the present study occurred in bursts lasting about 6 min with contraction frequencies of up to 5 per minute. The reasons for these differences are unclear, but it may be significant that the earlier studies focused on times after CT had induced hypersecretion, a time when there have been long-term increases in the excitability of some enteric neurons (Gwynne et al., 2009). By contrast, our study focused on the period prior to the onset of CT-induced hypersecretion and reflects more immediate effects of the toxin on the enteric nervous system.

One thing that both our data and the previous studies clearly agree on is that CT differentially modifies propulsive and segmenting motor patterns. This is highlighted by the major differences in time course of effects of CT on the two motor patterns. Propulsive motility evoked by CT occurs early in the exposure (Figure 2A), while luminal decanoic acid takes 40-90 min to induce segmentation (Figure 4, see also Gwynne et al., 2004). Segmentation induced by CT plus granisetron has a similar slow onset (Figure 2A). Amino acids also evoke a slow onset segmentation (Gwynne and Bornstein, 2007b), which is not due to a delay in activation of the enteric circuitry, as amino acids rapidly excite neural reflexes when applied to the mucosa (Gwynne and Bornstein, 2007a). The discrimination between CT-induced propulsive activity, and the suppression by CT of decanoic acidinduced segmentation, strongly suggests that CT selectively excites a neural circuit responsible for propulsive contraction patterns. However, CT does not act directly on terminals of enteric neurons, because CT does not penetrate the mucosa after 90 min in the lumen (Gwynne et al., 2009).

\section{MECHANISMS MEDIATING CT-INDUCED PROPULSIVE MOTOR ACTIVITY}

The temporal pattern of propulsive contractile activity seen in the presence of CT (with or without granisetron) suggests that this is regulated by two distinct pacemakers. Bursts of propulsive contractions alternate with regular periods of quiescence and CT increases the durations of the bursts and the frequencies of contractions within them, but has no effect on the quiescent periods. This suggests there is a rhythmically active driver circuit that determines the timing of the alternating contractile activity and quiescence and this activates or inhibits a propulsive pattern generator to initiate and coordinate the propulsive contractions. This is similar to the contractile activity seen with decanoic acid or amino acids in the lumen where periods of quiescence separate mixed segmentation and propulsion, and propulsive contractions often occur in bursts (Gwynne et al., 2004; Gwynne and Bornstein, 2007b). Thus, three different luminal stimuli may each activate both the driver pacemaker and the propulsive pacemaker circuits. Nutrients also activate a segmentation pacemaker circuit, but this 
is largely inhibited by CT. Which neurons are involved in these different pattern generators is still unclear, but modeling indicates that the oscillators responsible for bursts of propulsive or segmenting activity are in the sensory components of the overall circuits (Chambers et al., 2008).

\section{ROLES OF 5-HT ${ }_{3}$ RECEPTORS AND 5-HT IN RESPONSES TO CT}

This study, together with a large body of literature, strongly implicates 5-HT and 5- $\mathrm{HT}_{3}$ receptors in both the motility and secretory effects of $\mathrm{CT}$, but the sites where $5-\mathrm{HT}_{3}$ receptors are acting are less clear. Several sites are possible. Myenteric intrinsic sensory neurons respond to mucosally applied 5-HT via $5-\mathrm{HT}_{3}$ receptors on their mucosal terminals (Bertrand et al., 2000; Bertrand and Bornstein, 2002), so CT-induced 5-HT release may activate these neurons thereby exciting both motor and secretomotor pathways. There are $5-\mathrm{HT}_{3}$ mediated fast excitatory synaptic potentials (EPSPs) in both myenteric neurons involved in excitatory motor pathways (Zhou and Galligan, 1999; Monro et al., 2002) and submucosal secretomotor neurons (Monro et al., 2004). Finally, several studies indicate that mucosal 5-HT release is depressed by blockade of $5-\mathrm{HT}_{3}$ receptors, whether that release is activated by CT (Turvill et al., 2000b), by blockers of specific serotonin reuptake (Minami et al., 2003) or by cisplatin (Endo et al., 1999). In guinea-pig, 5-HT triggers mucosal 5 - $\mathrm{HT}$ release and this too is blocked by $5-\mathrm{HT}_{3}$ antagonists (Gebauer et al., 1993).

The route of administration of granisetron in the present study was chosen to preferentially block $5-\mathrm{HT}_{3}$ receptors at the level of the mucosa and the mucosal terminals of intrinsic sensory neurons. This was based on the observation (Tuladhar et al., 1997) that luminally applied 5- $\mathrm{HT}_{3}$ antagonists have different effects to those of the same antagonists applied via the bathing solution. The enhanced motility seen when CT and granisetron are added together is unlikely to be due to block of $5-\mathrm{HT}_{3}$ mediated fast EPSPs in myenteric neurons. Indeed, as these neurons are in excitatory

\section{REFERENCES}

Abdu, F., Hicks, G. A., Hennig, G., Allen, J. P., and Grundy,D. (2002). Somatostatin sst 2 receptors inhibit peristalsis in the rat and mouse jejunum. Am. J. Physiol. 282, G624-G633.

Argenzio, R. A., and Whipp, S. C. (1981). Effect of Escherichia coli heat-stable enterotoxin, cholera toxin and theophylline on ion transport in porcine colon. J. Physiol. (Lond.) 320, 469-487.

Bertrand, P.P., and Bornstein, J. C. (2002). ATP as a putative sensory mediator: activation of intrinsic sensory neurons of the myenteric plexus via $\mathrm{P} 2 \mathrm{X}$ receptors. J. Neurosci. 22, 4767-4775.

Bertrand, P. P., Kunze, W. A. A., Furness, J. B., and Bornstein, J. C. (2000). The terminals of myenteric intrinsic primary afferent neurons of the guineapig ileum are excited by 5-HT acting at 5-HT3 receptors. Neuroscience 101, 459-469.

Buchheit, K.-H. (1989). Inhibition of cholera toxin-induced intestinal secre-

pathways (Monro et al., 2002; Neal and Bornstein, 2007), block of $5-\mathrm{HT}_{3}$ mediated EPSPs would be expected to depress motor activity, rather than enhance it.

Our data, however, do not discriminate between granisetron acting on terminals of intrinsic sensory neurons or at another site to block 5-HT release. Activation of 5- $\mathrm{HT}_{3}$ receptors in the mucosal region clearly excites a pathway that inhibits propulsive motility, but propulsive motility excited by CT is not mediated via $5-\mathrm{HT}_{3}$ receptors. Perhaps the simplest explanation is that CT induces 5-HT release from the mucosa to excite a monosynaptic inhibitory reflex pathway that runs from the mucosa to the circular muscle (Gwynne and Bornstein, 2007a). Ongoing activation of this reflex would depress excitatory drive to the muscle thereby preventing generation of propulsive activity. Blockade of $5-\mathrm{HT}_{3}$ receptors would prevent this inhibitory reflex allowing more propulsive activity. How this translates to longer active periods and higher frequencies of contractions within episodes without altering either propagation speed or the durations of the intervals between contraction episodes will require careful further analysis.

In conclusion, luminal CT induces bursts of propulsive contractions, but suppresses nutrient-induced segmentation, in isolated guinea-pig jejunum. In contrast to the hypersecretion evoked by $\mathrm{CT}$, which manifests slowly and is blocked by the $5-\mathrm{HT}_{3}$ antagonist granisetron, the enhanced propulsive motility is rapid in onset and greatly enhanced by granisetron, indicating that CT excites at least two distinct pathways. The effects of granisetron and the suppression of nutrient-induced segmentation suggest that in addition to exciting secretomotor pathways and a propulsive motility pattern generator, CT excites a pathway that inhibits intestinal motility and may involve a $5-\mathrm{HT}_{3}$ receptor.

\section{ACKNOWLEDGMENTS}

This work was supported by a grant (566642) from the National Health and Medical Research Council (Australia).

tation is mediated by serotonin and cholecystokinin in isolated guineapig small intestine. Auton. Neurosci. $149,42$.

Endo, T., Minami, M., Kitamura, N., Teramoto, Y., Ogawa, T., Nemoto, M., Hamaue, N., Hirafuji, M., Yasuda, E., and Blower, P. R. (1999). Effects of various 5-HT3 receptor antagonists, granisetron, ondansetron, ramosetron and azasetron on serotonin (5-HT) release from the ferret isolated ileum. Res. Commun. Mol. Pathol. Pharmacol. 104, 145-155.

Farthing, M. J. (2000). Enterotoxins and the enteric nervous system-a fatal attraction. Int. J. Med. Microbiol. 290, 491-496.

Farthing, M. J. (2002). Novel targets for the control secretory diarrhoea. Gut 50(Suppl. 3), III15-III18.

Field, M., Fromm, D., Al-Awqati, Q., and Greenough, W. B., and III. (1972). Effect of cholera enterotoxin on ion transport across isolated ileal mucosa. J. Clin. Invest. 51, 796-804.
Gebauer, A., Merger, M., and Kilbinger, H. (1993). Modulation by $5-$ HT3 and 5-HT4 receptors of the release of 5-hydroxytryptamine from the guinea-pig small intestine. Naunyn Schmiedebergs Arch Pharmacol. 347, 137-140.

Gwynne, R. M., and Bornstein, J. C. (2007a). Local inhibitory reflexes excited by mucosal application of nutrient amino acids in guinea-pig jejunum. Am. J. Physiol. Gastrointest. Liver Physiol. 292, G1660-G1670.

Gwynne, R. M., and Bornstein, J. C. (2007b). Mechanisms underlying nutrient induced segmentation in isolated guinea-pig small intestine. Am. J. Physiol. Gastrointest. Liver Physiol.292, G1162-G1172.

Gwynne, R. M., Ellis, M., Sjövall, H., and Bornstein, J. C. (2009). Cholera toxin induces sustained hyperexcitability in submucosal secretomotor neurons in guinea pig jejunum. Gastroenterology 136, 299-308.

Gwynne, R. M., Thomas, E.A., Goh, S.M., Sjövall, H., and Bornstein, J. C. (2004). 
Segmentation induced by intraluminal fatty acid in isolated guinea-pig duodenum and jejunum. J. Physiol. (Lond.) 556, 557-569.

Hennig, G. W., Costa, M., Chen, B. G., and Brookes, S. J. H. (1999). Quantitative analysis of peristalsis in the guineapig small intestine using spatio-temporal maps. J. Physiol. (Lond.) 517, 575-590.

Janssen, P. W., Lentle, R. G., Hulls, C., Ravindran, V., and Amerah, A. M. (2009). Spatiotemporal mapping of the motility of the isolated chicken caecum. J. Comp. Physiol. B, Biochem. Syst. Environ. Physiol. 179, 593-604.

Keating, D. J., and Spencer, N. J. (2009). Release of 5-hydroxytryptamine from the mucosa is not required for the generation or propagation of colonic migrating motor complexes. Gastroenterology 138, 659-670, e652.

Kordasti, S., Sapnara, M., Thomas, E. A., Lindstrom, E., Forsman, M., Bornstein, J.C., and Sjövall, H. (2006). Effects of cholera toxin on the potential difference and motor responses induced by distension in the rat proximal small intestine in vivo. Am. J. Physiol. Gastrointest. Liver Physiol. 290, G948-G958.

Lentle, R. G., Janssen, P. W., Asvarujanon, P., Chambers, P., Stafford, K. J., and Hemar, Y. (2008). High-definition spatiotemporal mapping of contractile activity in the isolated proximal colon of the rabbit. J. Comp. Physiol. B, Biochem. Syst. Environ. Physiol. 178, 257-268.

Lentle, R. G., Janssen, P. W., Goh, K., Chambers, P., and Hulls, C. (2010). Quantification of the effects of the volume and viscosity of gastric contents on antral and fundic activity in the rat stomach maintained ex vivo. Dig. Dis. Sci. doi: 10.1007/s10620-010-1164-y.
Lundgren, O., and Jodal, M. (1997). The enteric nervous system and cholera toxin-induced secretion. Comp. Biochem. Physiol. A Physiol. 118, 319-327.

Mathias, J. R., Carlson, G. M., Bertiger, G., Martin, J. -L., and Cohen, S. (1977). Migrating action potential complex of cholera: a possible prostaglandininduced response. Am. J. Physiol. 232, G529-G534.

Mathias, J. R., Nogueira, J., Martin, J. L., Carlson, G. M., and Giannella, R. A. (1982). Escherichia coli heat-stable toxin: its effect on motility of the small intestine. Am. J. Physiol. 242, G360-G363.

Minami, M., Taguchi, S., Kikuchi, T., Endo, T., Hamaue, N., Hiroshige, T., Liu, Y., Yue, W., and Hirafuji, M. (2003). Effects of fluvoxamine, a selective serotonin re-uptake inhibitor, on serotonin release from the mouse isolated ileum. Res. Commun. Mol. Pathol. Pharmacol. 113-114, 115-131.

Monro, R. L., Bertrand, P. P., and Bornstein, J. C. (2002). ATP and 5-HT are the principal neurotransmitters in the descending excitatory reflex pathway of the guinea-pig ileum. Neurogastroenterol. Motil. 14, 255-264.

Monro, R. L., Bertrand, P.P., and Bornstein, J. C. (2004). ATP participates in three excitatory post-synaptic potentials in the submucous plexus of the guineapig ileum. J. Physiol. (Lond.) 556, 571-584.

Mourad, F. H., O’Donnell, L. J., Dias, J.A., Ogutu, E., Andre, E. A., Turvill, J. L., and Farthing, M. J. G. (1995). Role of 5-hydroxytryptamine type 3 receptors in rat intestinal fluid and electrolyte secretion induced by cholera and Escherichia coli enterotoxins. Gut 37, 340-345.
Neal, K. B., and Bornstein, J. C. (2007). Mapping serotonin inputs to enteric neurons of the guinea pig small intestine. Neuroscience 145, 556-567.

Neal, K. B., Parry, L. J., and Bornstein, J. C. (2009). Strain-specific genetics, anatomy and function of entericneural serotonergic pathways in inbred mice. J. Physiol. (Lond.) 587, 567-586.

Reeves-Darby, V. G., Turner, J. A., Prasad, R., Chopra, A. K., Chary, P., Clench, M. H., Peterson, J. W., and Mathias, J. R. (1995). Effect of cloned Salmonella typhimurium enterotoxin on rabbit intestinal motility. FEMS Microbiol. Lett. 134, 239-244.

Roberts, R. R., Bornstein, J. C., Bergner A. J., and Young, H. M. (2008). Disturbances of colonic motility in mouse models of Hirschprung's disease. Am. J. Physiol. Gastrointest. Liver Physiol. 294, G996-G1008.

Roberts, R. R., Ellis, M., Gwynne, R. M., Bergner, A. J., Lewis, M., Beckett, E. A. H., Bornstein, J. C., and Young, H. M. (2010). The first intestinal motility patterns in fetal mice are not mediated by neurons or interstitial cells of Cajal. J. Physiol. (Lond.) 588, 1153-1169.

Tuladhar, B. R., Kaisar, M., and Naylor, R. J. (1997). Evidence for a 5-HT3 receptor involvement in the facilitation of peristalsis on mucosal application of 5-HT in the guinea-pig isolated ileum. Br. J. Pharmacol. 122, 1174-1178.

Turvill, J.L., Connor, P., and Farthing, M.J. G. (2000a). Neurokinin 1 and 2 receptors mediate cholera toxin secretion in rat jejunum. Gastroenterology 119 1037-1044.

Turvill, J. L., Connor, P., and Farthing, M. J. G. (2000b). The inhibition of cholera toxin-induced 5-HT release by the 5-HT(3) receptor antagonist, granisetron, in the rat. Br. J. Pharmacol. 130, 1031-1036.
Turvill, J.L., Wapnir, R.A., Wingertzahn, M. A., Teichberg, S., and Farthing, M. J. G (2000c). Cholera toxin-induced secretion in rats is reduced by a soluble fiber gum arabic. Dig. Dis. Sci. 45, 946-951.

Turvill, J. L., Mourad, F. H., and Farthing, M. J. G. (1998). Crucial role for 5-HT in cholera toxin but not Escherichia coli heat-labile enterotoxin-intestinal secretion in rats. Gastroenterology 115 , 883-890.

Zhou, X., and Galligan, J. J. (1999). Synaptic activation and properties of 5-hydroxytryptamine3 receptors in myenteric neurons of guinea-pig intestine. J. Pharmacol. Exp. Ther. 290, 803-810.

Conflict of Interest Statement: The authors declare that the research was conducted in the absence of any commercial or financial relationships that could be construed as a potential conflict of interest.

Received: 01 May 2010; paperpending published: 29 June 2010; accepted: 16 August 2010; published online: 28 September 2010.

Citation: Fung $C$, Ellis $M$ and Bornstein JC (2010) Luminal cholera toxin alters motility in isolated guinea-pig jejunum via a pathway independent of 5-HT3 receptors. Front. Neurosci. 4:162 doi:10.3389/ fnins.2010.00162

This article was submitted to Frontiers in Autonomic Neuroscience, a specialty of Frontiers in Neuroscience.

Copyright (C) 2010 Fung, Ellis and Bornstein. This is an open-access article subject to a non-exclusive license between the authors and Frontiers Media SA, which permits use, distribution and reproduction in other forums, provided the original authors and source are credited and other Frontiers conditions are complied with. 